GEOSPORT FOR SOCIETY
$\begin{aligned} & \text { GEOSPORT } \\ & \text { SOCIETY }\end{aligned}$
Scientific Journal founded in 2014 under aegis of University of Oradea (Romania),
University of Debrecen (Hungary), University of Gdánsk (Poland)
ISSN 2393-1353
Edited by Oradea University Press
1, University Street, 410087, Oradea, Romania
Journal homepage: $h$ ttp://geosport.uoradea.ro

\title{
Sport and tourism facing the covid-19 pandemic
}

\author{
Maia MARGVELASHVILI*
}

1. Georgian State Teaching University of Physical Education and Sport, Department of Sport Management, 49 I. Chavchavadze Avenue, 0162 Tbilisi, Georgia, e-mail: margvel.m@gmail.com

* Corresponding author

Citation: Margvelashvili, M. (2021). Sport and tourism facing the covid-19 pandemic. Geosport for Society, 14(1), 21-27. https://doi.org/10.30892/gss.1403-067

Article history: 12.01.2021; Revised: 25.03.2021; Accepted: 10.05.2021, Available online: 21.05.2021

\begin{abstract}
The present study focuses on understanding the current research on the sports and tourism facing the COVID-19 pandemic. A review of the contemporary literature is considered to identify and classify research that focuses on the sports and tourism industries in the time of Covid19. The primary purpose of review was to identify and analyze the findings of relevant studies that are addressing defined research question. Restrictions imposed on the spread of the virus have affected all aspects of human life, including sports and tourism. As a result of the pandemic, we have severely restricted travel, canceled sports events, empty hotels, closed theaters, restaurants, cafes, and bars. That has had devastating consequences for the sports and tourism industries. Above limitations have made two things lucid - the desire of people to get out of the house and have the opportunity to travel beyond their daily movement, and recognition that physical activity and the ability to watch sports event, are a significant factor in supporting and ensuring the wellbeing of the people. These concepts are discussed in detail. Also, the matter of promoting electric scooters as an alternative to vehicles for urban mobility is discussed. The study proposes that at this early stage, while the pandemic is not yet about to recede, as evidenced by the current state of the world, it is too early to draw any far-reaching conclusions. But in this context, some basic concepts formed for further analysis of the issue. Undoubtedly, life after the pandemic will be quite different, and it is time for tourism and sports policymakers and organizers to start preparing for that.
\end{abstract}

Keywords: Covid-19, sports, tourism, physical activity, sports event, alternative transportation

\section{Introduction}

In January 2020, the World Health Organization declared Covid-19 an international threat to public health. And a few weeks later, it was recognized as a pandemic with 118 thousand infected and 4300 dead in 114 countries. In March, Europe became the epicenter of the virus, after which it spread to America and spread around the world. There are currently 88 million infected and 1 million 900 thousand dead worldwide (Worldometer, 2021). 
233.879 cases of Covid-19 are confirmed in Georgia at present. 223.276 infected have already fully recovered, while 2,666 have died. ${ }^{1}$

The virus that caused the global pandemic, against which there was neither vaccine nor cure, brought strict isolation measures to deal with it. Restrictions imposed on the spread of the virus have affected all aspects of human life, including sports and tourism. As a result of the pandemic, we have severely restricted travel, canceled sports events, empty hotels, closed theaters, restaurants, cafes, and bars. That has had devastating consequences for the sports and tourism industries. However, due to their nature, it is known that they characterized by rapid recovery (Cooper et al., 2005), and upon the end of the pandemic, both industries will occupy leading positions in the world economy, although with some adjustments, which are quite hard to predict at this stage and require significant observation and analysis.

The present study focuses on understanding the current research on the sports and tourism industries facing the COVID-19 pandemic. A review of the contemporary literature is considered to identify and classify research that focuses on the sports and tourism industries in the time of Covid-19. The primary purpose of review was to identify and analyze the findings of relevant studies that are addressing defined research questions.

For researchers in physical activity, health, wellbeing, sports, and tourism, above limitations have made two things unambiguous: (a) The desire of people to get out of the house and have the opportunity to travel beyond their daily movement, which, of course, was much more limited than in normal circumstances, and (b) Recognition that physical activity and the ability to watch sports, especially sports events, are a significant factor in supporting and ensuring the wellbeing of the people. Taken together, both observations revealed that sport and tourism could play an important role in supporting the response to Covid-19, as well as being an important lesson and example that could influence future response to other public issue policies (Weed, 2020).

\section{Methodology}

The literature review conducted using Google Scholar and WHO COVID-19 databases on the impact of Covid-19 on sports and tourism industries. The study selected twenty nine publications with participants from eleven countries. The following research question has guided this review: what impact has Covid-19 on sports and tourism industries.

There has been a lot of discussion and debate among the authors over the years about the exact definition of sports tourism. To move from precise definition to conceptualization and better characterize sports tourism, Weed and Bull (2004) suggested that sports tourism is better understood as arising from the unique interaction of activity, people, and place. An accurate definition of sports tourism is less significant for our analysis than identified concepts. The fact is that the sense of movement and place, the activity, its interdependence with the place, the experience received, and all of the above together contribute to human wellbeing.

\footnotetext{
${ }^{1}$ https://civil.ge/archives/342486
} 
In all of the above concepts, and given the role of sport and tourism in the Covid-19 response process, these interactions seem to be significant and the key to the sense of wellbeing that people and policymakers strive to achieve during a pandemic.

In this regard, the proposed review discusses two areas: a) sports events and b) physical activities and travel.

\section{Result}

As the impact and spread of Covid-19 became clearer in February and March 2020 , sports event hosts and administrations began discussing whether to postpone or cancel their events. Perhaps most important among them was the discussion of the Tokyo Olympic and Paralympic Games, which was planned for July 24, 2020.

Initially, the International Olympic Committee and other administrations, such as the World Athletics Council, suggested that it was not necessary to consider canceling the Games until the Covid-19 impact was clarified (McCurry, 2020). Herein, this position has been maintained for quite some time, despite growing evidence of a devastating global impact of the virus. This decision was also strange according to the criteria by which it was made. The reasons given for not canceling included the need to protect the income of elite athletes' and the rescheduling of events in the busy international sports calendar; whilst also commenting that despite increasing lockdown restrictions in many countries, it was necessary to allow athletes to continue training so that their preparation for the Games would not be impaired (BBC Sport, 2020). They did not envisage the international movement of significant masses of people, which posed such an event, nor the obvious threat to the health of athletes, their family members and the encirclement. Finally, the decision to postpone the Tokyo Games was made on March 24, 2020. Thus, if we want major sports events to play a positive role in the economy and society, decisions about their holding must be made with the necessary consideration of the problems of society. The fact that there has been no immediate response to the world's most significant threat to public health was a big accusation and an important lesson for the future.

Strict lockdown measures taken by various countries around the world meant that local leagues and international sports events, which usually attracted both traveling live spectators and large television audiences, were abruptly discontinued. That has left sports fans who suppose that 'being there' is always significant, without favorite sports spectacles, which has caused nostalgia in many countries around the world (Weed, 2010).

The principal theme of nostalgia caused by lockdown is not only the longing for the past but also the hope and expectation that impressions of the past will return in the future. Boym (2008) has termed this restorative nostalgia that linked to the role of hope as a positive and uplifting emotion (Lazarus, 1999).

Given the role of restorative nostalgia in sports events and their reactivation for the wellbeing of the people, the UK Government has supported the launch of elite sports tournaments as lockdown loosened, but behind closed doors, for broadcast (TV) only (HM Government, 2020). 
But, for example, watching live football play at empty stadiums at home, as restriction measures still prohibit the gathering of more than a few socially distanced people, has the potential for bizarre isolation. It is probably not essential if the person just wants to watch the game, but if he/she also wants to share his/her experience with someone - he/she will be disappointed.

Department of Economic and Social Affairs of the United Nations on May, 2020, in their Policy Brief №73 on The impact of COVID-19 on sport, physical activity and well-being and its effects on social development, has issued following recommendations to: ${ }^{2}$

1. Sporting federations and organizations. Governments and intergovernmental organizations may provide sports federations, clubs and organizations around the world with guidance related to safety, health, labor and other international standards and protocols that would apply to future sport events and related safe working conditions. This would allow all stakeholders to work cooperatively as a team with the objective to address the current challenges and to facilitate future sports events that are safe and enjoyable for all.

2. Professional sport ecosystem. The sport ecosystem, comprising of producers, broadcasters, fans, businesses, owners and players among others, need to find new and innovative solutions to mitigate the negative effects of COVID-19 on the world of sport. This includes finding ways to engage with fans in order to ensure safe sport events in the future while maintaining the workforce, creating new operating models and venue strategies.

Hopefully, governments and organizations will take timely steps to implement these recommendations completely.

The second direction concerns physical activities and travel.

In most countries of the world, no matter how strict the lockdown measures were, some exceptions were made for some types of physical activity or exercise. In the early stages of lockdown, the UK, like many other countries, has limited such physical exercises (for example, only up to an hour per day, near home, with only one family member) but, were broadly limited to walking, jogging, or cycling.

The reaction turned out to be quite surprising. A survey commissioned by Nuffield Health found that more than three-quarters of people in the UK chose a new form of exercise in addition to walking, jogging, or cycling - activities at home such as yoga, weight loss exercises, and home treadmills (Nuffield Health, 2020). Not surprisingly, walking exercise turned out to be the most popular activity. Herein, almost two-thirds of people reported that physical exercises were significant for their mental health and wellbeing.

In the same UK, in the first weeks after the introduction lockdown, one of the most critical aspects of public debate became the rules of exercise outside and access to green spaces. While those whose homes were close to such green spaces could freely use it, it proved impossible for others who needed transportation to do so. It has given rise to a discussion about the social and health inequalities created (Duncan et al., 2020).

\footnotetext{
2 https://www.un.org/development/desa/dpad/publication/un-desa-policy-brief-73-the-impact-of-covid-19-onsport-physical-activity-and-well-being-and-its-effects-on-social-development/
} 
These debates have illustrated the importance of not only physical exercises but also the places where these exercises were carried out (Atkinson et al., 2016). The impact of exercising on wellbeing in natural green areas greatly outweighs the impact of exercising in urban areas (Barton et al., 2016). So, as it turned out, achieving wellbeing is also linked to moving to the places that are perceived to be different from home.

It suggests that the impact of sports tourism on wellbeing is even broader than previously conceived and maybe an obvious shortcoming in what might be designate as everyday sports tourism.

Strict lockdown restrictions have led to the shortening of all motorized travel types, with air travel experiencing the broadest reduction. However, UK data showed that vehicle use fell by two-thirds in the first month of restrictions. Although restrictions loosened in the summer and people started working, vehicle use at the end of June was only 75\% before the lockdown rate (Department of Transport, 2020). The same data also showed that taking advantage of bicycles as a type of transportation increased by an average of $50 \%$ to $100 \%$, and in some weeks (mostly in the good weather) by more than $200 \%$. These data have sparked significant debate over whether the experience of severe restrictions will lead to sustained growth in more sustainable forms of travel.

It does not seem to be a coincidence to increase bicycle use by reducing vehicle use by two-thirds due to restrictions. Hopefully, such intensive use of bicycles will continue after the return of vehicles.

\section{Discussion}

Alleviating the constraints caused by the pandemic has highlighted the need for individual, low-emission transport that allows for social distance. An electric scooter can be considered as such because it is a fun and eco-friendly way to move for short distances.

Improving pedestrian conditions, arranging bicycle paths, and promoting small electric scooters can reduce dependence on vehicles. The rapid development of digital technologies has made it very easy and convenient for citizens to use electric scooters.

Currently, electric scooter sharing systems are already available in more than 100 cities in 20 countries. Europe and the US are leading by this figure. According to studies, by 2024 , there will be 4.6 million electric scooters in operation.

Numerous cities around the world are actively implementing ambitious scooter-sharing schemes. After people avoided public transport due to the pandemic, electric scooters appeared in Tbilisi and Batumi. Electric scooters are actively establishing themselves, becoming more and more popular and increasing their number on city streets and parks.

The scooter-sharing system "Scroll" first appeared in the capital of Georgia on April 27, 2020. It became an alternative to many other means of transport due to public transport restrictions (Kvashilava, 2020).

Electric scooters were promoted as a green alternative to vehicles for short distances. It is noteworthy that after the use of electric scooters, $39 \%$ of consumers 
travel less by vehicles. In the cities of Georgia, a scooter can be considered as a transport means that can freely replace a vehicle for short distances. For achieving this, it is necessary to make it more affordable and secure.

It should be noted, however, that with the increase in the number of electric scooters, the number of road accidents associated with them has increased. Electric scooters on the sidewalk pose a danger to pedestrians, wheelchair users, especially the weak eyesight persons.

Electric scooter-sharing companies pay close attention to sustainability issues. Some of them are introducing the use of renewable energy in the operation system, improving the durability of scooters through better design, etc.

For example, the company Bird, which has about 2,000 scooters already operating in Georgia, says that its latest models of electric scooters can last up to two years, while the first models are marked by about three or four months of durability. Recently, the company Lime promised that by 2030 its fleet will be $100 \%$ powered by an electric motor. The fulfillment of the promise started in Paris, where only eco-friendly transport operates the system. The main challenge of the electric scooter sharing service is its availability to a broad segment of citizens.

During the pandemic, sales of electric scooters increased in Finland, Ireland, and the UK, although their use in the streets of two latter countries is still illegal. The UK is not the only country that makes electric scooters part of its post-pandemic transport strategy. That is what happened in Australia and Colombia. Bogota has eased regulations on electric scooters for service providers. Buenos Aires supports the use of bicycles and scooters when traveling short distances. Rome had its first electric scooters in May. According to one of the mayors, after the changes caused by the pandemic, the ruling circles should encourage new means of mobility.

The Italian government's Covid-19 working group has partnered with Helbiz the electric scooter company, which supports mobility through social distance, and says the paradigm needs to be changed and the state's priority should be to provide citizens with wellbeing and mobility alternatives that allow them to move around without compromising the sustainability element. The government is offering subsidies to city residents to buy electric scooters. It will be perfect introducing such an approach in other countries as well.

\section{Conclusions}

The presented analysis revealed that sport and tourism play a significant role in supporting the response to Covid-19 and become an important lesson and example, which may influence solving other community-wide problems in future.

It is clear that at this early stage, while the pandemic is not yet about to recede, as evidenced by the current state of the world, it is too early to draw any far-reaching conclusions. But in this context, some basic concepts formed for further analysis of the issue. Undoubtedly, life after the pandemic will be quite different, and it is time for tourism and sports policymakers and organizers to start preparing for that.

Recommendations of the UN Department of Economic and Social Affairs, provided in their Policy Brief №73, indicate the significance and necessity of such preparation. 


\section{References}

Atkinson, S., Fuller, S., \& Painter, J. (2016). Wellbeing and place. 274 p., London: Routledge.

Barton, J., Bragg, R., Wood, C., \& Pretty, J. (2016). Green exercise: Linking nature, health and wellbeing. 228 p., London: Routledge.

BBC Sport. (2020). Tokyo Olympics \& coronavirus: Lord Coe says too early to decide on cancellation (March 19). Available at https://www.bbc.co.uk/sport/olympics/51958640 (Retraived on November $\left.29^{\text {th }}, 2020\right)$.

Boym, S. (2008). The Future of Nostalgia. New York: Basic Books.

Cooper, C. P., Fletcher, J., Wanhill, S., Gilbert, D., \& Shepherd, R. (2005). Tourism: principles and practice (3rd ed.), 810 p., Pearson Education.

Covid-19: Georgia Live Blog. Available at https://civil.ge/archives/342486 (Retrieved on January 7, 2021).

Department of Economic and Social Affairs of the United Nations, May, 2020, Policy Brief №73 on The impact of COVID-19 on sport, physical activity and well-being and its effects on social development, Available at https://www.un.org/development/desa/dpad/publication/un-desa-policy-brief-73the-impact-of-covid-19-on-sport-physical-activity-and-well-being-and-its-effects-on-socialdevelopment/ (Retraived on December 12, 2020).

Department of Transport. (2020). Transport use by mode: Great Britain, since March 1, 2020. Available at https://www.gov.uk/government/statistics/transport-use-during-thecoronavirus-covid-19pandemic (Retrieved on December 6, 2020).

Duncan, P., McIntyre, N., \& Cutler, S. (2020). Coronavirus park closures hit BAME and poor Londoners most (The Guardian, April 10). Available at https://www.theguardian.com/uknews/2020/apr/10/coronavirus-park-closures-hit-bame-and-poor-londoners-most (Retrieved on December 6, 2020).

HM Government. (2020). Our plan to rebuild: The UK Government's COVID-19 recovery strategy. London: HM Government.

Kvashilava, G. (2020). Future of Electric Scooters in Georgia. Available at https://publika.ge/article/eleqtroskuterebis-momavali-saqartveloshi/ (Retrieved on December 3, 2020).

Lazarus, R. S. (1999). Hope: An emotion and a vital coping resource against despair. Social Research, 66(2), 653-678.

McCurry, J. (2020). Tokyo 2020 organisers fight false rumours Olympics cancelled over coronavirus crisis. The Guardian, January 31. Available at https://www.theguardian.com/world/2020/feb/01/tokyo-2020organisers-fight-false-rumours-olympics-cancelled-over-coronaviruscrisis (Retrieved on June 29, 2020).

Nuffield Health. (2020). Over half of Brits have taken up a new form of exercise during lockdown, with many vowing to continue with their new regimes $(10$ May). Available at https://www.nuffieldhealth.com/article/over-half-of-brits-have-taken-up-a-new-form-of-exercise-duringlockdown-with-many-vowing-to-continue-with-their-new-regimes (Retrieved on December 12, 2020).

Weed, M. E. (2010). Sport fans and travel - is 'being there' always important. Journal of Sport \& Tourism, 15(2), 103-109.

Weed, M. E., \& Bull, C. J. (2004). Sports tourism: Participants, policy \& providers (1st ed.). 351 p., Oxford: Elsevier.

Weed, M. E., (2020). The role of the interface of sport and tourism in the response to the COVID-19 pandemic. Journal of Sport \& Tourism, 24 (2), 79-92.

Worldometer. (2021). COVID-19 Coronavirus Pandemic. Available at https://www.worldometers.info/coronavirus/ (Retrieved on January 7, 2021). 